\title{
Faz diferença como a gente pensa: aspectos da resistência forjada no entrecruzar cosmológico das tradições afroameríndias em Campina Grande, Paraíba
}

\author{
Jussara Carneiro Costa \\ Professora do Departamento de Serviço Social \\ Universidade Estadual da Paraíba \\ Lucas Gomes de Medeiros \\ Graduando em História \\ Universidade Estadual da Paraíba
}

\begin{abstract}
Resumo: As provocações descoloniais enfatizam a necessidade de procurarmos em tradições cosmológicas não homogeneizadas pela colonialidade ocidental, alternativas epistêmicas, políticas e éticas. No trabalho há reflexões tecidas a partir de investigações sobre a acomodação de marcadores da diferença nos espaços articulados por tradições afro-ameríndias em Campina Grande, Paraíba, Brasil. Argumentamos que os sistemas epistemológicos articulados e acessados por essas tradições comportam técnicas ricas em reconfigurações da subjetivação que adensam a resistência aos efeitos articulados da sexualização e racialização de corpos e espaços.
\end{abstract}

Palavras chave: cosmologia; afro-ameríndia; tradição; diferença; resistência. 


\title{
It makes a difference as we think: Aspects of the forged resistance in the cosmological interbreeding of the Afro-American traditions in Campina Grande, Paraíba
}

\begin{abstract}
Decolonial provocations emphasize the need to seek epistemic, political, and ethical alternatives in cosmological traditions not homogenized by Western coloniality. In this work there are reflections woven from investigations on the accommodation of markers of difference in spaces articulated by afroamerindian traditions in Campina Grande - PB (Brazil). Wearguethat the access to the epistemological systems articulated by these traditions entails techniques that are rich in reconfigurations of subjectivation that deepens the resistence to the articulated effects of sexualization and racialization of bodies and spaces.
\end{abstract}

Keywords: cosmology; afro-amerindian; tradition; difference; resistance.

\section{Qué importa cómo pensamos: aspectos de resistencia forjados en lo entrecruzamento cosmologico de las tradiciones afroameríndias en Campina Grande, Paraíba}

Resumen: Las provocaciones de coloniales há cenhincapié em La necesidad de buscar em lãs tradiciones cosmológicas no homogeneizadas por La colonialidade occidental alternativas epistémicas, políticas y éticas. En este trabajo hay reflexiones tejidas a partir de investigaciones acerca deelalojamiento de marcadores de diferencia em espacios articulados por tradicionesafroamerindiasen Campina Grande, PB (Brasil). Argumentamos que el acceso a los sistemas epistemológicos articulados por estas tradiciones implica técnicas ricas em reconfiguraciones de subjetivación que aumentan la resistencia a los efectos articulados de lasexualización y laracialización de cuerpos y espacios.

Palabras clave: cosmología; afro-amerindia; tradición; diferencia; resistencia. 


\section{Os caminhos que nos levaram aos terreiros - introdução}

O feminismo que emerge da década de 1970 problematiza a maneira como se encontram articulados modelos interpretativos da vida, estruturas epistemológicas, discursos sobre a diferença, processos de racialização e sexualização e organização das dinâmicas de poder em níveis locais e globais. $\mathrm{O}$ período compreendido entre as décadas de 1960 e 1980 abrigou um conjunto articulado de dinâmicas que provocaram inflexões profundas na maneira de problematizar o que chamamos de social. Nesse contexto, se aglutinou um conjunto de interpelações enunciadas de distintas localizações subalternas, através de eventos que incidiram de forma determinante na maneira como se traduz e se teoriza a tessitura dos processos sociais.

Elucidando as imbricações entre a forma como atribuímos significados ao mundo e as complexas engrenagens de controle historicamente instaladas pelo ocidente, desvelam a constituição de um modelo epistemologicamente constituído sobre o binarismo "natureza" e "razão" - como capacidade de racionalização - posicionadas como polos dicotômicos e assimetricamente fixos, cabendo ao polo inferior a condição de exterior constitutivo daquele tido como superior, mais especificamente, a função de atestar sua superioridade.

Tal operação possibilitaria os processos de identificação e diferenciação, bem como as dinâmicas desiguais de poder que lhes são associadas. Além disso, serviria de base às diversas acomodações históricas da relação saber-poder, articulando marcadores sociais de espécie, raça, sexualidade e gênero, dentre outros, através dos quais produz um sistema de identificação que opera por meio de cadeias analógicas polarizadas pelo binômio natureza/razão. A estrutura epistemológica permitiria falar sobre as diferenças, convertê-las em fontes de desigualdade, constituindo a base da narrativa colonialista.

As ações articuladas em torno da constituição do Combahee River Collective (1974-1980) e da compilação dos textos This Bridge Calledmy Back/Esta puente, mi espalda (1981) coordenado pela teórica cultural Gloria Anzaldúa e a poeta feminista Cherrie Moraga, assim como, o standpoint e o princípio da inseparabilidade das lutas constituem exemplos da mudança radical nos paradigmas epistemológicos, teóricos e políticos a partir do feminismo e no âmbito do próprio movimento. De diferentes localizações raciais, territoriais, dissidências sexuais e de gênero, subalternizados pela história inauguram um jeito "diferente" de problematizar o que chamamos de "realidade". Nesse exercício, evidenciam a relação entre organização políticoeconômica e a regulação dos comportamentos, apontando como processos de racialização e sexualizacão dos corpos e territórios construíram estratégia chave de manutenção de uma ordem de dominação.

Vozes que se colocam desde uma perspectiva descolonial1, como a do sociólogo porto riquenho Ramón Grosfoguel (2008, 2012), reiteram a estratégia epistêmica como crucial no desenho das dinâmicas globais e a problematização feminista acerca do entrelaçamento dos processos de humanização, racialização, sexualização e organização das relações de poder que conformam as dinâmicas sociais, políticas e econômicas das desigualdades regionais. Enfatizam, além disso, a necessidade de problematizar o investimento na desqualificação e 
destruição de cosmologias e "sistemas-mundo" que desafiam a lógica ocidentalista implantada nos processos de colonialidade. Para Grosfoguel (idem), somente contemplando tais aspectos temos de fato uma epistemologia comprometida com a descolonialidade.

As reflexões da filósofa indiana Gayatri Spivak (2010), do grupo sul asiático de estudos subalternos, apontam a existência de "subjetividades precárias" delineadas nos marcos da "violência epistêmica" colonial que desqualifica os conhecimentos e formas de apreensão do mundo da pessoa colonizada, surrupiando-lhe a possibilidade da enunciação. Das reflexões da autora e contribuições apresentadas por Grosfoguel, podemos inferir que no retorno aos elementos constituintes dessas cosmologias podemos encontrar importantes chaves para pensar a resistência. Sua desqualificação estaria, portanto, relacionada justamente às potencialidades que carregam.

Assertiva semelhante também será encontrada nas reflexões desenvolvidas pelo filósofo Michel Foucault (2007), no que chamou de insurgência de saberes dominados. A historiadora Joan Scott (1994) ressalta que a noção de saber não se refere apenas a ideias, mas a instituições, estruturas, práticas cotidianas e rituais específicos, a um modo de ordenar o mundo que não antecede a organização social, mas é inseparável dela (SCOTT, 1994). Ou seja, são independentes e autônomos em relação às ciências e habitam outros tipos de discursos, correspondendo, portanto, a

[...] uma série de saberes que tinham sido desqualificados como não competentes ou insuficientemente elaborados: saberes ingênuos, hierarquicamente inferiores, saberes abaixo do nível requerido de conhecimento ou de cientificidade (FOUCAULT, 2007, p.170).

Embora não se vincule à desconstrução da descolonialidade, como aponta a crítica de Grosfoguel (2008, 2012), o filósofo francês também credita o ataque sistemático a esses saberes à potencialidade subversiva que comportam e, por essa razão, recomenda o urgente investimento na realização de suas genealogias.

No Brasil, a partir do que denomina de perspectivismo ameríndio, o antropólogo Eduardo Viveiros de Castro (1996) fornece uma rica caracterização da cosmologia ameríndia, adensando o argumento de que o investimento sistemático na sua extinção busca apagar outras possibilidades de se viver e se relacionar com o mundo, desafiando a normatização da vida requerida pelos sistemas de dominação ancorados na ordem cosmológica imposta pela colonialidade.

Para o autor, o paradigma moderno baseado na distinção entre natureza e cultura não se mostra suficiente para compreender povos, modos de sociabilidade e tradições que se baseiam em outros modos de percepção, em outras cosmologias, pois "a distinção clássica entre natureza e cltura não pode ser utilizada para descrever dimensões ou domínios internos a cosmologias não ocidentais, sem passar antes por uma crítica etnológica rigorosa" (VIVEIROS DE CASTRO, 2002, p.348).

Viveiros de Castro (idem) sugere o termo multinaturalismo como saída conceitual, problematizando as cosmologias modernas e o multiculturalismo. Enquanto, em linhas gerais, o multiculturalismo imputa à cultura ou ao sujeito a condição de formas universais e à natureza ou ao objeto, a forma particular, o multinaturalismo ou as cosmologias ameríndias, suporia uma unidade do espírito e uma diversidade dos corpos. 
Uma contribuição fundamental auferida das reflexões de Viveiros de Castro está na admoestação para que não procedamos a uma inversão simétrica, enfatizando a necessidade de recombinar e dessubstancializar as categorias natureza e cultura, uma vez que no pensamento ameríndio apresentam significados diferentes de seus análogos ocidentais (VIVEIROS DE CASTRO, 2002).

A partir das reflexões apontadas, é possível deduzir que nos organizamos ainda a partir de imperativos culturais e históricos dos discursos que nos instituem como periféricos. Por essa razão acolhemos as provocações descoloniais que apontam a necessidade de investirmos na construção de nossas próprias ferramentas conceituais teóricas e metodológicas para analisar a realidade e nela intervir.

As provocações se constituíram no mote para o delineamento do Programa de Extensão Universitária “Tod@s Junt@s Somos Fortes: somando saberes e esforços pelo enfrentamento ao racismo, misoginia e violência contra LGBTTIs no compartimento da Borborema-PB”. Executado desde o início de 2014, no âmbito da UEPB, com apoio do MEC/Sisu/Proext, vem articulando ações de investigação e intervenção pelo esforço de problematizar dinâmicas articuladas de sexualização e racialização no compartimento da Borborema, Paraíba2.

Considerando que a maioria das pessoas envolvidas na iniciativa compartilha a experiência de, simultaneamente, estudar e exercer algum tipo de ativismo, acordamos coletivamente o compromisso em tomar como temas de investigação e produção acadêmica questões relacionadas ao foco do Programa. Além disso, também pactuamos o compromisso com a execução de uma agenda de eventos para ampliar espaços de enunciação de pessoas e grupos com quem mantemos interlocução ao longo das ações.

Investimos num denso e permanente processo de formação, executado mediante a realização de cursos de extensão universitária, encontros para orientação de leituras, investigações, análise de problemas, produção de textos e rodas de diálogo3.

As reflexões aqui apresentadas localizam-se nesse conjunto articulado de esforços e brotaram de investigação desenvolvida no âmbito do PIBIC/UEPB/CNPq (2015-2016). Sob o título O que marca a diferença também faz a resistência: interconexões de raça, gênero, sexualidade e geração no Agreste e Cariri Paraibano, a investigação articulou dois subprojetos4 que buscaram analisar como marcadores sociais de gênero, raça e sexualidade reverberam na organização de grupos de rezadeiras, benzedeiras e comunidades de terreiro, organizadas em torno das tradições afro-ameríndias na microrregião de Campina Grande; como interagem com outros marcadores sociais e são apropriadas na produção de resistências coletivas.

Realizamos um denso esforço de reconstituição genealógica dos temas, observando as práticas sociais que conferem tessitura às questões articuladoras da investigação. Nesse processo, a interlocução com os sujeitos que habitam ou percorrem os espaços de pesquisa foi fundamental para o desenvolvimento da

2 A Borborema constitui uma unidade geomorfológica montanhosa que corta os estados do Rio Grande do Norte, Paraíba, Pernambuco e Alagoas. A pesquisa alcançou um grupo de cidades entre a mesorregião do Agreste e a microrregião do Cariri paraibano.

3 Até o momento o esforço resultou na produção de 7 trabalhos de conclusão de curso, em âmbito de graduação, 2 em âmbito de pós-graduação (em nível de especialização, por docentes de ensino médio da rede pública estadual), 5 pesquisas de Iniciação Científica, aprovação de 6 projetos de pós-graduação em nível de mestrado e 1 de doutorado.

4 "Além de Macumbeiro é Bicha: Marcadores da Diferença nos terreiros de Campina Grande, Paraíba" e "O Gênero da Resistência nas Rezadeiras de Boa Vista, Paraíba”. As investigações prosseguem no biênio 2016-2017 com a pesquisa "Eu quero ver o que a jurema tem, quero ver o que a jurema dá: memória para a resistência na Arte de se Fazer Mestra na Tradição da Jurema Sagrada”. 
investigação e para o adensamento de sua significação. Recorremos a uma variedade de técnicas, consulta a textos, documentos, observação direta, registro e sistematização. O trabalho se construiu com base em visitas frequentes aos espaços, sistematizadas num diário de campo que nos forneceu ótimas indicações de itinerários a serem percorridos para realizar a genealogia das experiências analisadas, cartografar seus modos de vida.

Por muito tempo, a historiografia deslegitimou a oralidade para referendar documentos de arquivos e textos escritos, entretanto, como recorrer a tais fontes históricas para atribuir voz a grupos cujas práticas são transmitidas pela oralidade ou, quando escritas, sob a ótica de um sujeito observador distante e não pertencente a tais realidades? Portanto, essa forma de registro vem se mostrando fundamental ao exercício de reflexões sobre todas as atividades que desenvolvemos, permitindo a sistematização de práticas invisibilizadas que não poderiam ser acessadas de outras maneiras.

\section{De ponto em ponto5 e de ponta a ponta, no axé todo mundo se encontra}

O toque teve início às dezesseis horas de vinte e nove de abril de 2015, no Templo de Umbanda Rainha das Matas/Ilê Axé Oyá Gigan ou na casa de Mãe Dé, como é conhecido o espaço. Os atabaques chamam. Primeiramente saudamos a Exu, o orixá da comunicação e dos caminhos, é ele quem nos ligará aos demais. Pés descalços, colares de contas, vestes brancas, casa pequena de arquitetura simples e convidativa, cores vivas em uma cortina florida na parede lateral.

Num recanto a esquerda, próximo a entrada do salão, uma mesa farta ostentava cigarros, champanhes, uvas roxas além de imagens de entidades alegres. Mais adiante, num altar fixo e em degraus, imagens das figuras regionais como o caboclo e o boiadeiro, velhos/as fumando cachimbo, crianças de pernas cruzadas e índios/as em posição de caça misturam-se ao cheiro adocicado do mel de rapadura e cachaça utilizados na fabricação da jurema6, das ervas misturadas ao fumo dos cachimbos utilizados no ritual.

Contemplando a presença do Cristo crucificado na parede do terreiro bem como o retrato da Virgem Maria, somos interpelado/as pelas provocações do antropólogo José Antônio Kelly Luciani (2016) que, ao observar a experiência dos indígenas Yanomami do Alto Orinoco na Amazônia venezuelana, afirma que esses não deixaram de se autorreconhecer como tal apesar das intensas trocas com a "sociedade nacional" ou povos criollos: a cultura hibrida Yanomami resultaria assim de trocas relacionais com os criollos e não de fusões com eles.

Tomando os Yanomami como exemplo etnográfico, Luciani (idem) provoca a reflexão a partir de uma teoria da antimestiçagem explorando formas mutuamente implicadas de hibridação social e mudança temporal Yanomami e criolla. Contrapor-se a mestiçagem significa problematizar a miscigenação, teoria científica da mistura biológica e sociocultural, que uma vez

5 Pontos são músicas cantadas em saudação ou invocação às entidades nos terreiros de Umbanda e Jurema Sagrada.

6 A jurema é um composto alcoólico que possui como principal ingrediente a planta de mesmo nome, uma leguminosa comum no bioma da caatinga, caracterizada por suas propriedades psicoativas. Essa bebida é utilizada em alguns rituais nos terreiros de umbanda e candomblé traçados com a jurema sagrada, um culto de pajelança paraibana herdado dos índios tabajara e potiguara. 
[...] assumida sem maiores problematizações, na qual a mestiçagem figura como a consumpção de diferentes entidades por meio de sua fusão, e como a produção de um novo tipo de pessoa, de povo, classe ou nação com qualidades físicas, sociais, morais ou espirituais distintas, a depender da ênfase (LUCIANI, 2016, p.25).

Em 20 de junho de 2015, na visita ao Ilê Asè Babá Obá Igbô, terreiro de Candomblé dirigido pelo babalorixá Antunes Caldas presenciamos um toque para os caboclos7. As entidades chegaram por volta das dezenove horas. $\mathrm{O}$ caboclo do Pai de Santo da casa, chamado Cangaruçu, e outro que atendia pelo nome de Seu Pena Branca em um dos filhos da casa. Os atabaques tocavam freneticamente convidando as pessoas presentes para ocuparem o centro do local.

Em meio a palmas, a caboclada dançava alegremente, fumando charuto e bebendo cerveja. Na ocasião, Cangaruçu misturava cachaça, mel e outros compostos desconhecidos para nós, preparando a jurema, posteriormente compartilhada com os/as filhos/as da casa e convidados/as. Do mesmo modo que chegaram em festa, em festa se despediram. A celebração que teve início com bebidas e cigarros foi encerrada com uma oração ao "Nosso senhor Jesus Cristo".

$\mathrm{Na}$ nossa primeira incursão aos terreiros, logo nos foi anunciado um universo rico e complexo marcado pela hibridização de elementos que remetem a conjunção de cosmologias africanas, indígenas/locais e de elementos do catolicismo e dissidências com o espiritismo kardecista. Para compreendê-lo faz-se necessário um esforço mínimo de nos situarmo em relação às práticas do Candomblé, da Umbanda e da Jurema Sagrada.

Como nos explica Pai Antunes, o Candomblé de afro-brasileira, tem os Orixás, Voduns e Nkices como divindades máximas. O uso das nomenclaturas varia de acordo com a nação e território de origem de tais cultos. Os Orixás são cultuados na nação Ketu e Nagô, remanescentes da Nigéria, os Voduns na nação Jeje, remanescentes do Daomé, e os Nkices na nação Angola que, como o próprio nome sugere, tem origem angolana e banto.

A Umbanda por sua vez, constitui-se como um conjunto de práticas e crenças que somam componentes cristãos, afro-brasileiros e do espiritismo kardecista. É importante enfatizar que foi a dissidência em relação à doutrina de Allan Kardec, no início do século XX, que lhe deu origem e, além disso, as razões que ocasionaram a dissidência. Em 15 de novembro de 1908 na Federação Espírita de Niterói, RJ, registrou-se a manifestação do Caboclo das Sete Encruzilhadas no médium Zélio Fernandino de Morais com o seguinte questionamento: "Por que repele a presença desses espíritos, se nem se quer se dignaram a ouvir suas mensagens? Será por causa de sua origem social e da cor?8”. Os questionamentos foram determinantes para a criação de um novo culto, no qual entidades entregavam suas mensagens. A chegada da Umbanda na região Nordeste, no final da primeira metade do século passado, coloca-a em contato direto com a tradição da Jurema Sagrada, com a qual passa a interagir.

A Jurema Sagrada, por sua vez, tem origem nas antigas pajelanças indígenas, sobretudo entre os Tabajaras e Potiguaras do litoral da Paraíba, Rio

\footnotetext{
7 O sociólogo Armando Vallado (2001) observa que"a origem do Candomblé de caboclo está apoiada no ritual de antigos negros africanos de origem banta que cultuavam inquices, divindades presas a terra, e que, na diáspora africana, perderam o sentido do culto no novo continente, obrigando-se a eleger outro antepassado que as substituísse. Assim, os caboclos, que são antigos índios que povoaram o Brasil, foram eleitos pelos escravos bantos como verdadeiros ancestrais da nova terra que lhes fora destinada a viver" (VALLADO, 2001, p.239). Pai Antunes, no entanto, alerta que o culto dos caboclos como arquétipos indígenas estão mais associados ao culto da Jurema Sagrada enquanto que "no [candomblé de] Angola são inquices brasileiras, são pais orientadores".

8 O site Colégio de Umbanda constitui uma boa e confiável fonte para pesquisa sobre a Umbanda no Brasil. Disponível em: <<http://colegiodeumbanda.com.br/index.php/umbanda/>>. Acesso em: 05/11/2016.
} 
Grande do Norte e Pernambuco. Os/as sacerdotes/isas mais antigos/as nos contam que esses povos Tupis cultuavam a variação da acácia como uma planta sagrada, mencionando sempre que esses povos indígenas acolhiam negros fugidos, esses contatos promoveram trocas fecundas de elementos e informações.

O contato entre a Jurema Sagrada e o catolicismo popular se deu gradativamente. Em sua constituição, também apresenta atualmente saberes caros às tradições indígenas locais e dos negros Nagôs de origem nigeriana que desembarcaram principalmente em Recife-PE. Advém dessa tradição o conhecimento das ervas e o ato de defumar com o cachimbo, bem como o uso da bebida chamada jurema, uma mistura de cachaça, ervas e cascas de árvores, mel e outros compostos com capacidade psicoativa. Já a adoração aos/as pretos/as velhos/as é remanescente da Umbanda, mas também integra o culto da Jurema Sagrada em algumas casas.

Entre espaços de Candomblés, Umbandas e Juremas, a cidade de Campina Grande conta com aproximadamente 400 terreiros, loci de sociabilidades tradicionais afro-ameríndias, não por acaso, escondidos em bairros periféricos. Na maioria das casas visitadas são cultuados Orixás de Candomblé e encantados da Jurema Sagrada, mas os rituais ocorrem em dias específicos e separados. Essa constatação configura inclusive uma das peculiaridades locais, as chamadas "casas traçadas", ou seja, espaços que abrigam tradições ligadas ao Candomblé e à Jurema Sagrada ao mesmo tempo. Alguns elementos da Umbanda como o culto de pretos/as velhos/as aparecem difundidos na Jurema Sagrada, o que leva a Juremeira e Yalorixá Goretti de Oxum Opará a crer que a mistura e junção entre as práticas subalternizadas resultam da troca de experiências entre povos de origem negra e indígena, as quais carregam em comum o fardo da perseguição por não praticarem o catolicismo regular, corroborando, portanto, para a existência de relações afroindígenas, nos termos delineados por Marcio Goldman (2014).

A complexidade é tanta que o que conseguimos apresentar constitui apenas um esboço dos aspectos que se sobressaltam num nível mais superficial e apressado de contato e, entretanto, apresenta densidade suficiente para nos permitir afirmar que a manutenção dessas comunidades em Campina Grande está relacionada ao fato de que melhoram condições de viver e habitar um lugar hostil. É possível supor que mecanismos advêm das possibilidades de subjetivação organizadas a partir de um conjunto de exercícios desenvolvidos com a finalidade de preparar os indivíduos para conviver com as realidades mais difíceis, a começar por onde se encontram localizadas as casas de axé, compostos por interações mantidas entre projetos epistemológicos inscritos nas cosmologias afro-ameríndias. Alguns desses elementos, articulados nas vivências do povo de santo, serão apresentados a seguir.

\section{"Quem aprende a amar o Orixá aprende a amar a natureza, quem não ama a natureza também não ama o Orixág”}

Nos itans10iorubanos Oxum aparece como a senhora das águas doces, as tempestades são ordenadas por Oyá, enquanto Xangô é a balança que tudo pesa,

9 Depoimento de Ângelo de Oxumaré, durante um toque no templo de Umbanda Rainha das Matas/Ilê Axé OyáGigan em 03 de outubro de 2015.

10 Narrativas acerca das histórias dos Orixás, seus domínios e arquétipos. 
o rei da justiça e o senhor das pedreiras, cabendo-lhes, portanto, respeito, admiração e reverência. Não podemos imaginar os Orixás apenas como representações imagéticas, as narrativas orais que os personificam não os distanciam da natureza. O sentido do sacrifício ritual, segundo Pai Antunes de Oxalá, diz respeito a "uma troca e transformação da energia vital dos animais para devolução aos Orixás e outras entidades", apontando para um reposicionamento na maneira de se perceber a natureza que nos terreiros é constantemente reverenciada e não dominada. Ao falar sobre o assunto no documentário Ori, a socióloga Beatriz Nascimento, enfatiza que

\begin{abstract}
"O ebó é dado para a terra. Todos os elementos vivos estão na terra e vão participar daquele banquete, que é o ebó. Vai ter ali vírus, vai ter ali micróbios, vai ter ali células que vão se decompor e se transformar em outras células...E esse é o princípio do Axé, da força!11
\end{abstract}

Nos rituais de Jurema Sagrada também estão presentes as oferendas para as entidades cultuadas. A ligação destas com a natureza se expressa em seus assentamentos, nas tronqueiras (pequenos troncos de árvore) que, segundo as sacerdotisas mais antigas, guardam a força e a sabedoria da entidade. Os troncos são de árvores específicas escolhidas pelos próprios espíritos. Estão mais as de árvores como jurema, angico e jucá, plantas comuns no semiárido nordestino, consideradas sagradas para o culto da Jurema Sagrada. Assim como os arquétipos de força no candomblé, entidades também recebem oferendas de alimentos, grãos e bebidas específicas.

A partir da critica feminista podemos perceber o porque do investimento na natureza como categorização desqualificadora nas tessituras das dinâmicas de poder por meio da articulação simultânea dos processos de humanização, racialização e sexualização. Como aponta a historiadora Nancy Stepan (1994), se na filosofia greco-romana mulheres são tidas como limitadas por natureza, assim como, os povos escravizados, no cristianismo "a negritude foi associada ao feminino, à escuridão da noite, à natureza, à feiura, à presença demoníaca e culpa, sendo a brancura associada à virtude, beleza, santidade e pureza" (STEPAN, 1994, p.77). Observa, no entanto, que com o surgimento do darwinismo social e da Eugenia, a nomeação da diferença e os arranjos entre os marcadores sociais que articula adquiriram nova conformação. No século XIX o gênero era notavelmente análogo à raça, de modo que a ciência podia usar a diferença racial para explicar a diferença de gênero e vice-versa. O leve peso do cérebro feminino e suas "deficientes" estruturas cerebrais seriam análogas às das raças inferiores, o que explicaria as baixas capacidades intelectuais da "raça" feminina.

Nesse contexto, as preocupações se deslocaram para o controle do processo de reprodução da espécie por meio de uma série de investimentos técnicos que conformaram o que Foucault (1988) denominou de dispositivo histórico da sexualidade. O filósofo enfatiza que, tomando a espécie como preocupação central, o sexo se constitui numa poderosa ferramenta de controle da reprodução e dos processos de subjetivação, cuja utilidade é fundamental à categorização dos corpos como normais ou anormais e, a partir disso, estabelecer sua disposição e circulação no espaço.

Conforme observa, o cerco à sexualidade deve ser compreendido em meio ao refinamento das técnicas de controle e disciplinamento que caracterizam a sociedade moderna, não se colocando sob o domínio direto de nenhuma 
instituição estatal, policial ou administrativa superior com poder jurídico legislador. O dispositivo da sexualidade é acionado para forjar uma subjetividade governável, daí o investimento nas normas sobre o corpo; por meio desse processo é que se institui a heteronormatividade. As novas estratégias de gestão da população demandam o investimento do Estado na constituição da sexualidade como aquilo que confere identidade social às pessoas "normais" ou "anormais", exercendo uma pedagogização dos corpos que se faz acompanhar pela necessária correspondência entre desejo, identidade de gênero e prática sexual, como base para a "heteronormatizar" os modos de se viver.

O sociólogo brasileiro Richard Miskolci (2012) demonstra de maneira contundente como ideais eugenistas embasaram a constituição do projeto de nação e a concepção do espaço republicano brasileiro, mediante o planejamento do processo de branqueamento populacional como política de Estado, conferindo características peculiares à arrumação do nosso dispositivo da sexualidade. Entretanto, se olharmos para a maneira como se organizou geopoliticamente a administração do espaço público nacional, veremos que esse dispositivo se particulariza ainda mais se consideradas as especificidades "regionais". Na genealogia da "invenção do Nordeste" realizada pelo historiador Durval Muniz de Albuquerque Junior (2007), é possível perceber o caráter peculiar do dispositivo da sexualidade efetivado na institucionalização do Nordeste como região. Embora o processo coincida com a expansão da eugenia no Brasil, se no eixo Sul/Sudeste as premissas evolucionistas foram utilizadas para justificar um processo de branqueamento controlado, no eixo Norte/Nordeste foram acionadas por elites locais para demonstrar o drama da "natural" inferioridade de tudo que é relacionado ao espaço e justificar os investimentos reivindicados para a institucionalização do Nordeste como região. As pretensões "civilizatórias" vinculadas à aplicação da eugenia no Sul/Sudeste não alcançaram, nos mesmos moldes, o eixo Norte/Nordeste. Por aqui não se verificou o investimento no ideal de branquitude requerido pela nação, como vemos no trabalho de Miskolci (2012). Por essa razão, o Nordeste passa a ser visto como o espaço que atualiza a memória de um passado que se pretende apagar. A pessoa nordestina será vista como rude, preguiçosa, pouco inteligente, dentre outros adjetivos depreciativos.

Como demonstrado por Albuquerque Junior (2007), essas concepções serão reiteradas no trabalho de vários intelectuais do Nordeste, reverberando especialmente na produção de uma literatura regionalista. A maneira como se retrata a relação de negros/as e indígenas com a natureza, bem como suas tradições culturais e práticas sagradas, se fez mediante a ridicularização ou elisão dos sistemas epistemológicos em que se encontram inscritas, produzindo estereótipos que ressaltam o caráter "ingênuo", "alegórico", "pitoresco" e "primitivo" desses povos. O "clássico" Nordestes, do sociólogo Gilberto Freyre, é singular nesse sentido:

\footnotetext{
A verdade é que ainda hoje os xangôs afro-brasileiros do Nordeste recordam em alguns dos seus cantos mais doces e dos movimentos de dança mais expressivos os velhos gestos de semear e de colher, o culto da terra, a alegria no trabalho agrícola, o regozijo pelo fruto ou pela espiga madura. Toda uma mística do trabalho agrícola (FREYRE,2004, p.89).
}

Esse quadro de leituras do "outro" baseado no determinismo biológico atualiza o pensamento já corrente no Brasil colonial. Não escapando à lógica, Freyre empresta sua contribuição à naturalização da ideia de que o conjunto das 
práticas culturais por aqui desenvolvidas atestam nossa "natural” vocação para o trabalho braçal. Em sua leitura, "Catucá12 surge diante de nós quase como uma afirmação da capacidade de negros para se adaptarem rapidamente aos trópicos americanos e a sombra de suas florestas mais profundas, em contraste com a incapacidade dos nórdicos" (FREYRE,2004, p.162). Tais investimentos discursivos reverberam nas dinâmicas de abjeção lançadas aos espaços de cultos afro-ameríndios na cidade de Campina Grande.

\section{Sobre resistências forjadas no entrecruzar cosmológico das tradições afroameríndias}

Em Campina Grande, o caso mais emblemático envolveu o anúncio do projeto de lei do vereador Olímpio Oliveira (PMDB), que em 2012 propôs na câmara municipal a proibição do "sacrifício animal" em rituais religiosos. $\mathrm{Na}$ ocasião, foram distribuídos panfletos com a ilustração de animais dos mais diversos (muitos não utilizados nos rituais religiosos) fugindo de um Pai de Santo que carregava uma faca na mão.

São costumeiros os ataques a esses espaços, especialmente quando a casa fica conhecida por ter filhos e filhas cujos corpos evidenciam de maneira mais enfática dissidências e trânsitos de gênero, como ocorre com o Ilè Asè Babá Obá Igbò, de Pai Antunes Caldas de Oxalufan. Na nossa primeira visita, ainda no final de julho de 2014, nos deparamos com uma narrativa que nos arrancou um misto de lamento e revolta. O Babalorixá recorda com desgosto os constantes ataques sofridos ao longo dos treze anos do terreiro: "semana passada dois caras encapuzados arremessaram pedras no teto e ano passado, num toque de caboclo, jogaram um coquetel molotov, o terreiro cheio de palha e com um monte de criança, a sorte é que estava chovendo".

Pai Antunes afirma com ironia ter comprado uma pasta grossa [pronunciando a palavra devagar e com forte entonação, como se dissesse "groooossa"] apenas para colecionar os boletins de ocorrência que acumula, dando a entender que nenhuma providência havia sido tomada pelas autoridades para enfrentar a situação. Na ocasião, o Fórum de Diversidade Religiosa da Paraíba estava reunido no terreiro para discutir alternativas de apoio à casa, a reunião foi interrompida pelo barulho de uma pedra arremessada ao telhado.

As observações de Pai Antunes reverberaram na nossa experiência. Na primeira visita ao seu Ilê, tentamos localizar o espaço perguntando à vizinhança e, por duas vezes, nos deparamos com situações nas quais as pessoas se benziam "em nome do pai do filho e do espírito santo" fazendo o gesto de cruzar a testa, o ventre e os ombros, antes de nos responder. Nas atividades que ocorreram durante o período junino - que na cidade de Campina Grande dura aproximadamente um mês e meio - do ano seguinte nos deparamos duas vezes com o ataque de bombas caseiras, aproveitando-se do período para camuflar o barulho.

Pai Antunes observa que as ameaças o acompanham desde o início. Lembra das dificuldades enfrentadas com pessoas da família por sua condição

12 Catucá era o nome genérico dado às áreas de floresta que margeavam as regiões de produção de açúcar e algodão da Zona da Mata de Pernambuco. Ela começava nos matagais e morros localizados na saída de Recife e Olinda para o interior, e seguia no sentido norte até Goiana, na divisa com a Paraíba. Neste caminho estavam localizados mais de 100 engenhos, inclusive os maiores e mais antigos da Província. Lá funcionavam os locais de esconderijo de escravos/as fugidos/as. 
de gay e candomblecista, enfatizando, no entanto,que sua maior dificuldade de relacionamento se dá com as pessoas evangélicas, sobretudo com os/as vizinhos/as que nunca aceitaram suas práticas religiosas no local. Recorda que chegou a ser ameaçado de morte e foi espancado por um colega de trabalho evangélico que, segurando suas guias13,apontou sua religião como prática maligna e o ameaçou de "acabar com sua raça". Para ele, a perseguição à sua casa resulta da associação de suas práticas religiosas à sua "condição sexual"14.

O babalorixá fala com carinho dos/as filhos/as de santo, Alexandra Saraiva, Vinnycius Queiroz (Natasha Fontinelly), Erick Queiroz (Laysa Whatson) e outras. Demonstrando que seu terreiro é majoritariamente composto por travestis, gays, drag queen's e lésbicas, recorda que o tráfego dos/as filhos/as pela rua que dá acesso ao espaço é geralmente seguido de expressões como "além de macumbeiro é bicha", "além de veado é macumbeiro", numa provocação disfarçada de sussurro dito para ser ouvido, pronunciadas pelos/as vizinhos/as.

Quando participamos dos rituais na sua casa pudemos ter uma dimensão do "impacto" sentido por sua vizinhança. Um dos rituais aguardados com maior entusiasmo pelos/as filhos/as da casa é a vista de uma Pomba Gira Cigana. 15 "Deram sorte, ela só vem a cada cinco anos, e quando vem. Elas demoram a vir, as ciganas andam demais" nos informa o Yawô (iniciado no Candomblé) Murilo de Oxum Ipondá.

O terreiro devidamente ornamentado com velas coloridas, baralhos ciganos, incensos de ervas, tudo disposto com cuidado. No centro, sobre uma toalha estendida ao chão estava Pai Antunes, melhor dizendo, a Pomba Gira Cigana que agora seu corpo habitava. Descalça, pulseiras brilhantes adornavam tornozelos, braços e ombros. $\mathrm{O}$ batom era discreto e usava um lenço amarelo na cabeça. Fumando e traçando seu baralho usa o tilintar do pequeno sino para chamar as pessoas presentes no recinto, uma a uma, para a consulta. Ao adentrarmos o espaço, depositávamos moedas num prato de zinco como saudação e reverência àquela visitante ilustre e rara.

As reconfigurações de gênero são recorrentes nas práticas afro-ameríndias, como nos revela o depoimento descontraído de Pai Carlos de Oxum, colhido após uma reunião do Programa de Extensão Todxs Juntxs Somos Fortes no Ilê Axé Oxum Opará/ Tenda de Umbanda Boiadeiro Zé Firmino16:

\begin{abstract}
Vocês estão me vendo assim, um homem forte de 1,74 m de altura, basta! Agora imagine isso virado em Maria Padilha (risos) ela dá uma cruzada de pernas que eu estando em mim num chego nem perto! Eu devo minha vida a ela, tem dia que falta as coisas lá no terreiro e eu peço a ela... Menina, levei um prejuízo de doze mil reais na compra de um carro, esse dinheiro dava pra fazer a festa dela e a comemoração dos 10 anos de obrigação. Aí eu me desesperei: "-como é que a pessoa tem uma rapariga de uma pomba gira que num livra a gente de uma dessas". Ai quando foi na festa de Seu Boiadeiro aqui em Goretti, Salomé17 veio e disse que não me preocupasse que o que eu tinha de perder já tinha perdido, agora eu só tinha a ganhar.
\end{abstract}

Posições sociais masculinos e femininos se fazem presentes nessas tradições, mas relativamente afrouxados em relação à heteronormatividade,

13 Fios de conta que representam os Orixás.

14 Registro da visita realizada em 28 de março de 2015

15 Entidade espiritual feminina que é tratada nos terreiros como a versão feminina de Exu e está geralmente ligada a questões amorosas. Seu culto tem origem na Umbanda, mas está presente também em algumas casas de Jurema.

16 Registro da visita realizada em 08.10.2014.

17 Pomba Gira da sacerdotisa Mãe Goretti de Oxum Opará. 
como nos ensina a Ialorixá Mãe Yara de Roximucumbi, cuja relação oficializada com um "rapaz" trans ou uma "mulher masculina"18, justifica que:

\begin{abstract}
Quando nos consagramos ao Orixá nos entregamos por completo sem haver distinção entre corpo e espírito, então somos concebidos por inteiro como homem ou mulher. Então para não causar constrangimento nas pessoas 'trans', por exemplo, basta tratar por Vòdúnsì ou Egbomi que são palavras usadas para se referir ao iniciado sem precisar fazer distinção de gênero. Mas mesmo assim homem recebe orixá feminino, mulher recebe orixá masculino.
\end{abstract}

Os terreiros se apresentam, dessa maneira, como espaço de trocas de experiências e des/re/subjetivações. Pai Antunes nos informa que ele ressalta sempre para o/as filho/as que a "junção" da sua "questão" sexual com uma prática religiosa discriminada aumenta mais ainda o preconceito, mas, lembralhes também que devem olhar o terreiro como um espaço para se fortalecer e para lutar contra isso.

$\mathrm{Na}$ ausência de livros escritos que acionam dogmas e padronizam rituais, percebemos nas tradições afroameríndias a oralidade como potente mecanismo na transmissão dos saberes ancestrais e suas potências. A narração cativante das histórias de orixás e entidades, os conselhos como parte intrínseca da Jurema, os banhos de ervas, os ritos de limpeza e os resguardos são condições de fortalecimento da "natureza individual de cada filho para que o corpo se fortifique e manifeste o sagrado no momento do transe", como nos ensina Pai Antunes.

As técnicas desenvolvidas a partir do encontro entre as tradições constituem um conjunto de práticas aparentadas com aquelas que Foucault (1994) denominou de "cuidados de si" para referir-se aos procedimentos identificados entre os gregos estóicos que envolvem exercícios aplicados pelas pessoas sobre si mesmas com o intuito de se fortalecerem; que configuram as técnicas de si e são efetivados por meio da escrita, leitura, meditação, exercícios físicos, períodos de abstenções, exame da consciência, dentre outros. Aparecem ao longo da história e não são limitadas ao campo filosófico, tampouco da ambição de teorizar. Na maioria das vezes surgem com a simples ambição do "homem" comum de tornar a vida mais agradável.

$\mathrm{O}$ interesse pelo tema tem a ver com o debate sobre o assujeitamento como traço constitutivo do "sujeito" formatado pela cultura ocidental. O cuidado de si reposiciona a discussão sobre a agência política na análise, e o interesse foucaultiano pela genealogia dos saberes dominados está relacionado à inspiração que podemos obter com as "técnicas de si" contidas nessas experiências.

Ao identificar que a "logística" da dominação é movida pelo controle dos processos de subjetivação, Foucault (2007) evidencia o investimento na fabricação de certo tipo de indivíduo e de ethos, por meio de um conjunto de técnicas de captura cada vez mais complexas e sofisticadas, aplicadas através dos aparatos institucionais, mas também configuradas para serem manejadas sozinhas. No inventário dessas tecnologias identifica um movimento de inflexão provocado por sua apropriação pelo cristianismo para serem usadas na conformação do "poder pastoral", demonstrando, dessa maneira, a possibilidade de seu uso para propósitos contrários àqueles que motivaram sua constituição. Daí a necessidade de acompanhamento minucioso de sua aplicação. O trabalho que o indivíduo exerce sobre si mesma adquire a forma de 
ascese, necessária para manter o corpo sempre vigilante para o combate a ser sustentado. A luta é, decididamente, por cada batalha, não há vitória final porque não há fim.

A ausência do texto escrito como base para o rito confere às tradições orais um caráter mais fluído e subjetivo. Alguns rituais remontam práticas ancestrais antigas e podem ser semelhantes em vários terreiros, enquanto outros são informados pelas memórias trazidas pelas entidades que acompanham cada lugar. As estórias e vivências são recriadas nas falas e atualizadas nas nossas vidas como aprendizado.

\section{"[...] Trabalha sem ninguém ver, sem ninguém ver, sem ninguém ver, trabalha sem ninguém ver [...]"}

No conjunto das técnicas de subjetivação desenvolvidas no entrecruzamento das tradições, merece destaque especial a cultura de manutenção do "segredo". Em dia de "obrigação19" o terreiro costuma ficar agitado. No Templo de Umbanda Rainha das Matas/Ilê Axé Oyá Gigan, a Yalorixá e Juremeira Mãe Dé interrompe um dos/as filhos/as que tentava explicar para nós em que consistia uma atividade da obrigação e suas finalidades ritualísticas. A manhã daquele sábado de 17 de agosto de 2014 já caminhava para o fim, numa cerimônia de iniciação à Jurema estavam presentes filhos/as de santo da sacerdotisa e convidado/as também praticantes da religião. Nessas circunstâncias, costuma-se redobrar o cuidado com o segredo que envolve certos rituais, o neófito senta-se em uma esteira de palha encostada na parede e a sacerdotisa conduz o ritual. Visivelmente irritada, encara o filho nos olhos com franqueza, respira fundo e, com ironia, entoa um ponto que ressalta a importância do segredo na tradição "o segredo da Jurema todo mundo quer saber, a Jurema é um pau sagrado, trabalha sem ninguém ver, sem ninguém ver, sem ninguém ver, trabalha sem ninguém ver...”

O segredo e a faculdade de resguardá-lo são indispensáveis nessa seara. As receitas de bebidas ritualísticas, orações, feitiços e encantamentos, as plantas e suas funções, a memória dos/as mestres/as da Jurema, são apenas alguns exemplos. Para ter acesso aos fundamentos dessas práticas se faz necessário um período de convivência e de preparação para a execução das responsabilidades. Como em outras práticas baseadas na oralidade, integra uma complexa ritualística por tratar-se de algo fundamental para manter a potência de saberes que se constituem como fonte de força e inspiração, os elementos que permitam reconstituir sistemas-mundo outros, utilizando uma expressão de Grosfoguel (2008). Além disso, configura táticas de resistência que contribuem para a manutenção dos lugares que os abrigam e os permitem atuar. Daí revelá-los somente a quem prove ser confiável, que tenha o "dom" e a coragem de se submeter aos exercícios que envolvem a preparação necessária para administrálo. Ao invés da propagação de uma verdade que se pretende universal, colabora na composição de uma subjetividade outra, que não obriga os indivíduos a compararem constantemente suas ações diárias com códigos de condutas 
morais normativamente pré-estabelecidos, características que marcam as profissões de fé católica e/ou exames de confissão, por exemplo.

Mãe Goretti de Oxum Opará alerta que tanto no Culto dos Orixás como na Jurema Sagrada existem segredos, fundamentos que as pessoas vão sabendo aos poucos. As tronqueiras guardam o segredo e a ciência dos mestres, muita coisa quando é revelada perde sua força. O segredo nessa religião é onde está a força de cada entidade e de cada filho20. Poderíamos inferir, portanto, que as estratégias de manutenção do segredo aparecem como elemento constitutivo das técnicas de subjetivação, permitindo escapar da obrigatoriedade da confissão que compõe a insidiosa capacidade de captura do poder pastoral, nos termos de Foucault (1995).

Em diálogo com Pai Antunes de Oxalufan, babalorixá do Ilê Axé Babá Obá Igbô, sobre os diversos espaços que o terreiro comporta, questionamos o motivo da porta do "quarto de santo" permanecer sempre fechada. O sacerdote alerta: "Candomblé é muito cochicho, num é só uma bater de palmas e tambores não. Os mistérios do Runcó veio com os africanos, o quarto de santo é onde estão guardados os fundamentos dos Orixás cultuados na casa”. Encerrando apressado o assunto, entendemos que o tema era delicado para ser tratado no momento. No meio da conversa voltou a enfatizar: "É o espaço onde a natureza dialoga com o interior de cada um, os rituais botam as pessoas em contato com elas mesmas, com os medos e as vontades que elas têm para que elas se fortaleçam individualmente e se preparem para a vida", e ainda lembra que "os negros africanos faziam os ebós e eram escondidos para enganar os senhores de engenho, aí eles passavam com aquelas oferendas dentro de um alguidar cobertas com um pano branco e ninguém desconfiava, pensavam que era uma comida, qualquer coisa, menos uma oferenda21".

\section{Considerações finais}

A interlocução com os terreiros em suas mais variadas tradições reafirma para nós que entender a cosmologia nas tradições afro-ameríndias de Campina Grande-PB nos possibilita condições de conhecer as estratégias criadas por esses espaços para subverter a norma que os colocou na condição de subalternos.

$\mathrm{O}$ envolvimento daqueles e daquelas que fazem as experiências pesquisadas se dá justamente para buscar nesses espaços alternativas que lhes permitam o adensamento das potências para (r)existir. Estas, por sua vez são encontradas num conjunto de práticas de cuidado de si presentes nas trajetórias e experiências de vida, pondo em xeque a funcionalidade de um sistema de controle que se organiza e se atualiza combatendo-as. É possível perceber que as estratégias de desqualificação das experiências investigadas se devem à potência questionadora que carregam.

\section{Bibliografia}

ANZALDUA, Gloria e MORAGA, Cherrie. This Bridge Called My Back Writings Radical Women of Color Editors. New York, Women of Color Press, 1981.

20 Depoimento coletado em 10/o8/2016, durante um ritual de Jurema Sagrada na Tenda de Umbanda Boiadeiro Zé Firmino/Ilê Axé Oxum Opará.

21 Depoimentos coletados em visita de 28 de março de 2015. 
ALBUQUERQUE JR, Durval Muniz. Preconceito contra a origem geográfica e de lugar: as fronteiras da discórdia. São Paulo, Cortez, 2007.

FOUCAULT, Michel. História da sexualidade I: A Vontade de Saber. Rio de Janeiro: Graal, 1988, 10 ed.

. “As técnicas de si”. Vol. IV. Gallimard, 1994.

. O sujeito e o poder. In. DREYFUS, Hubert L \& RABINOW, Paul. Michel Foucault: uma trajetória filosófica para além do estruturalismo e da hermenêutica. Rio de Janeiro: Forense Universitária, 1995.

. Em Defesa da Sociedade: Curso no Collége de France (19751976). São Paulo: Martins Fontes. 1999.

. A Hermenêutica do Sujeito. São Paulo. Martins Fontes, 2004.

- Sobre a história da sexualidade. In. FOUCAULT, Michel. Microfísica do Poder São Paulo, GRAAL, 2007.

FREYRE, Gilberto. Nordeste: aspectos da influência da cana sobre a vida e a paisagem do Nordeste do Brasil. São Paulo. Global, 2004. $7^{\mathrm{a}} \mathrm{ed}$.

GOLDMAN, Márcio. A relação afroindígena. Cadernos de campo, São Paulo,UNESP, n. 23, p. 1-381, 2014.

GROSFOGUEL, Ramón. Para descolonizar os estudos de economia política e os estudos pós-coloniais: transmodernidade, pensamento de fronteira e colonialidade global. Revista Crítica de Ciências Sociais, Coimbra, Portugal, n. 80, p 115-147, março. 2008.

. Para descolonizar as esquerdas ocidentalizadas: para além das esquerdas eurocêntricas rumo a uma esquerda transmodernadescolonial. Contemporânea, São Carlos-SP, UFSCAR, v.2, n.2, p. 327-362, Jul-Dez. 2012.

HARAWAY, Donna. Saberes Localizados: a questão da ciência para o feminismo e o privilégio da perspectiva parcial. Cadernos Pagu. Campinas-SP, UNICAMP, vol. 5, 1995, pp 07-41.

LUCIANI, José Antonio Kelly. Sobre a antimestiçagem. Tradução de Nicole Soares, Levindo Pereira e Marcos de Almeida Matos. Curitiba, PR, Núcleo de Antropologia Especulativa, 2016.

MISKOLCI, Richard. O desejo da nação: masculinidade e branquitude no Brasil de fins do sec. XIX. São Paulo, Annablume, 2012.

VALlaDO, Armando. Candomblé de Caboclo em São Paulo. In PRANDI, Reginaldo (org.), VALLADO, Armando e \& SOUZA, André Ricardo de. Encanteira brasileira. Rio de Janeiro, Pallas, 2001.

RICARDO, Carlos Alberto (ed.). 2000. Povos Indígenas no Brasil, 1996200O. São Paulo: Instituto Socioambiental. 832 p. (mapas, ilustrações, gráficos, tabelas). 
SCOTT, Joan Wallach. Prefacio a Gender and Politics of History. Cadernos Pagu, Campinas, SP, vol. 3, 1994, pp. 11-27.

SPIVAK, Gayatri Chakravorty. Pode O Subalterno Falar? Belo Horizonte, UFMG, 2010.

STEPAN, Nancy L. Raça e Gênero: o papel da analogia na ciência. In. HOLLANDA, Heloisa Buarque. Tendências e impasses, o feminismo como critica da cultura. Rio de Janeiro: Rocco, 1994, pp. 72-96.

VIVEIROS DE CASTRO, Eduardo. Perspectivismo e multinaturalismo na América indígena IN: A inconstância da Alma selvagem e outros ensaios de antropologia. São Paulo: CasacNaify, 2002. pp. 347-399.

Recebido em 20/11/2016. Aprovado em 24/12/2016. 